\title{
Functionalization of Multi-walled Carbon Nanotube by Treatment with Dry Ozone Gas for the Enhanced Dispersion and Adhesion in Polymeric Composites
}

\author{
Jung-Hwan Kim and Byung Gil Min^ \\ Department of Nano-Bio Textile Engineering, Kumoh National Institute of Technology, Gumi, Gyeongbuk 730-701, Korea \\ ^e-mail:bgmin@kumoh.ac.kr \\ (Received November 8, 2010; Accepted December 1, 2010)
}

\begin{abstract}
A method of functionalization of multi-walled carbon nanotube (MWNT) at room temperature using dry ozone gas is described. The resulting MWNT were characterized by Fourier transform infrared, x-ray photoelectron spectroscopy, and scanning electron microscopy. Combined to these analyses and solubility in liquids, it could be concluded that the dry ozone gas exposure introduces polar functional groups such as carboxylic groups to MWNT similar to acidic modification of MWNT. Particularly, the stable dispersion of MWNT in water after ozone treatment above a critical level could be obtained, implying potential bio-application. The hydrophilic functional groups on the MWNT introduced by ozone oxidation were helpful in improving the interaction with functional groups in PA6 such as $-\mathrm{NH}_{2}$ and $-\mathrm{CONH}$ - resulting in improved mechanical properties.
\end{abstract}

Keywords : MWNT, Ozone, Functionalization, Polyamide 6

\section{Introduction}

Carbon nanotubes (CNT) can be used as effective reinforcing fillers for high performance polymer composites because of their unique one-dimensional structure with excellent mechanical and thermal properties [1-4]. However, due to their large aspect ratio and chemical inertness, CNTs are difficult to disperse into common solvents and polymer matrices [5]. As the performance of a CNT/polymer nanocomposite depends on the dispersion of CNTs in the matrix and interfacial interactions between the CNT and the polymer, surface modification is often required.

Chemical modification is typically employed to introduce covalent functional groups. CNT can be modified either covalently or non-covalently by introducing various functional groups on their non-reactive surfaces via oxidative processes. The mixture of concentrated sulfuric and nitric acid was used as one of the most conventional oxidizing agents to introduce oxygen-containing moieties onto the CNT surface [6,7]. The oxidized CNT has shown the improved dispersion and interfacial behavior with various polymer matrices [8,9]. However, the liquid wastes generated from these wet oxidation processes together with the tedious purification procedures would greatly limit their further development for industrial application.

On the other hand, the gas-phase oxidation, such as ozone $\left(\mathrm{O}_{3}\right)$ oxidant, is an environmental friendly and low-cost route to introduce oxygen containing groups onto $\mathrm{CNT}$ even for mass production. Smalley et al. reported the Fourier transform infrared (FTIR) spectroscopic studies of oxidation and etching of single-walled carbon nanotubes using $\mathrm{O}_{3}$ at room temperature [10]. Najafi et al. [11] reported that treatment of multi-walled carbon nanotube (MWNT) with UV-ozone (UVO) under ambient conditions could impart a dramatic effect on the nature of the surface oxidation, leading to the production of quinines, esters, and hydroxyl functional groups. However, most of reports on ozone treatment of CNT were carried out in wet state or by UV-ozone equipment. Thus, there was little report on the treatment of CNT using dry gas-phase ozone supplied by an ozonegenerator.

In the present work, we report the effect of ozone gasphase oxidation to functionalize the surface of MWNT on the morphology and properties of polyamide6 (PA6)/MWNT composites.

\section{Experimental}

\subsection{Materials}

The MWNT (NC7,000) were supplied by Nanocyl Co. (Belgium), which had been produced using chemical vapor deposition, and the purity was higher than $90 \%$, and was 
used as received. PA6 (KOPA-PA6) was provided by Kolon Plastics Co. (Korea).

\subsection{Ozone treatment of MWNT}

Ozone treatment of MWNT was carried out by flowing ozone gas into a glass chamber filled with MWNT powder using an ozone generator (LAB series-1) from Ozone-tech Co. (Korea) for $6 \sim 30 \mathrm{~h}$ at room temperature. For the operation of the ozone generator, oxygen gas was supplied to the generator at a rate of $11.7 \mathrm{~g} / \mathrm{hr}$ under $1 \mathrm{~kg} / \mathrm{cm}^{2}$ resulting in amount of ozone generation, $137.7 \mathrm{~g} / \mathrm{m}^{3}$.

\subsection{Preparation of Nylon $6 / M W N T$ composites}

The PA6/MWNT composites were prepared by an extrusion process and subsequently mould the compounded products by injection molding. Samples with $1 \sim 5 \mathrm{wt} \%$ of MWNT were melt-mixed using a co-rotating twin screw extruder (Bau-Tech Co., Korea). The temperature zones starting from the hopper to the die were set at $220^{\circ} \mathrm{C}, 230^{\circ} \mathrm{C}$ and finally, $240^{\circ} \mathrm{C}$ at the die and the screw speed was about $200 \mathrm{rpm}$. The extrudate was immediately quenched in a water bath at room temperature. The quenched samples were pelletized by cutting. After being pelletized and dried, the composite samples were injection-molded using an injection molding machine (Dongsin Mechnics Co., Korea). The temperature of the barrel was set at $240^{\circ} \mathrm{C}$.

\subsection{Characterization}

Fourier transform infrared (FT-IR) spectroscopic measurements were performed using a FTIR spectrometer (Bruker). The FT-IR spectra of raw MWNT and ozone modified MWCNTs were obtained in transmittance mode by placing a small amount of the materials in $\mathrm{KBr}$ pellets.

The change in the shape of MWNT with ozone treatment and fracture morphology of nylon6/MWNT composites were observed using FE-SEM (JEOL, JSM-6500) at an accelerating voltage of $15 \mathrm{kV}$. Percentage of elemental $\mathrm{O}$ and fractions of major carbon-oxygen functional groups was analyzed by X-ray photoelectron spectroscopy (XPS). XPS measurement was performed using Thermo Fisher, K-alpha with $\mathrm{Mg} \mathrm{Ka}(1253.6 \mathrm{eV})$ radiation at a energy step of $0.05 \mathrm{eV}$.

Thermogravimetric analysis was carried out with a TA Instrument Inc. SDT Q600 under nitrogen gas flow at a heating rate of $20^{\circ} \mathrm{C} / \mathrm{min}$. Measurements of tensile mechanical properties of the prepared nanocomposites were performed on an Instron 4467 head speed of $50 \mathrm{~mm} / \mathrm{min}$. The results of 10 tests were averaged. Impact properties of the nanocomposites were measured using a notched Izod test machine (Tinius Olsen, US/92T) with $6 \mathrm{~mm}$ width of specimens.

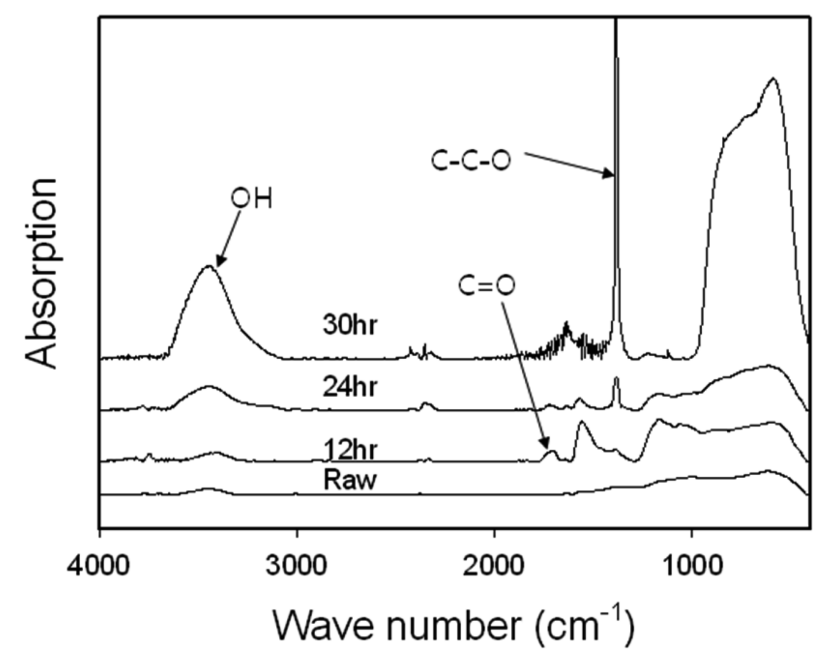

Fig. 1. FT-IR spectra of raw and ozone treated MWNT up to 30 hrs.

\section{Results and Discussion}

\subsection{Surface functionalities of MWNT by ozone treatment}

The FT-IR absorption spectra of the raw MWNT and those treated with ozone for up to $30 \mathrm{~h}$ are compared in Fig. 1. It is clear that the spectra of these MWNTs show no significant bands before the ozone treatment but display some apparent bands after the treatment. The spectra show absorption peaks at 1650 and $1730 \mathrm{~cm}^{-1}$ corresponding to the stretching vibration of $\mathrm{C}=\mathrm{O}$ from the carboxylic acid groups $(-\mathrm{COOH})$. This absorption peak was also very clear and strong for the MWNT oxidized with $\mathrm{HNO}_{3}$, whereas it was much weaker with the MWNT oxidized with $\mathrm{H}_{2} \mathrm{O}_{2}$ and $\mathrm{KMnO}_{4}$ [12]. A broad peak at approximately $3400 \mathrm{~cm}^{-1}$ can be assigned to $\mathrm{OH}$ stretch from carboxylic groups $(-\mathrm{COOH}$ and $-\mathrm{COH})$ while the band at $2300 \sim 2400 \mathrm{~cm}^{-1}$ is associated with $-\mathrm{OH}$ stretch from strongly H-bonded-COOH [13]. In the case of our modified MWNT, these characteristic bands appeared with significantly higher intensity, according to the degree of modification. This was attributed to the increased number of carboxylic acid groups generated at the surface of the MWNT after the ozone treatment, which implies that the effect of ozone treatment is a kind of oxidation similar to those in strong acids. On the other hand, excessive treatment can causes not surface modification but severe damage to destroy the graphitic layers structure of MWNT, as shown in the case of treatment for $30 \mathrm{~h}$ [14]. From the FT-IR results, $12 \mathrm{~h}$ was selected to be optimum time for modification of MWNT by ozone.

XPS measurements are required for further quantitative analysis. Fig. 2 shows the XPS spectra of raw and ozonetreated MWNT. The oxygen peak intensity of the ozonetreated MWNT was notably increased as compared to that of 


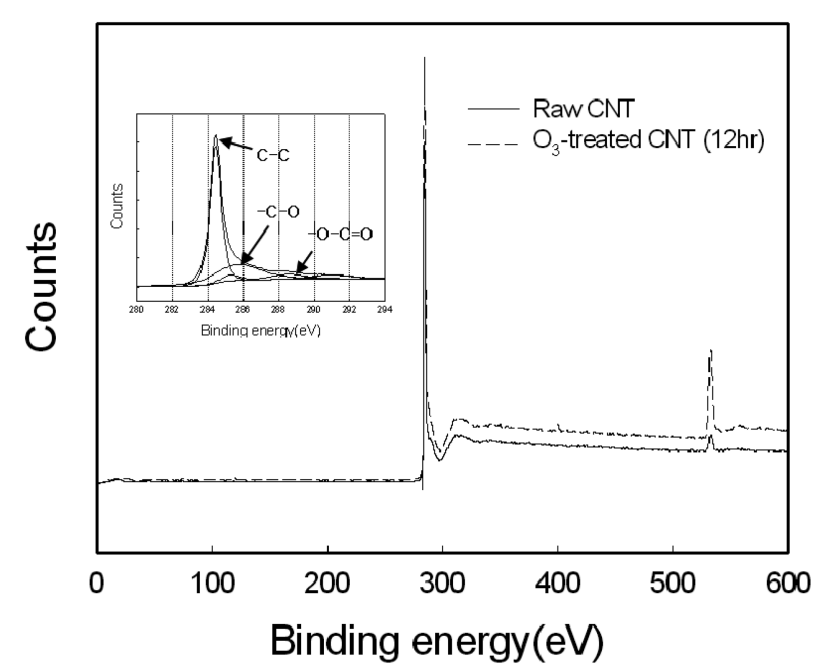

Fig. 2. XPS spectra of showing change of $\mathrm{C} 1 \mathrm{~s}$ and $\mathrm{O} 1 \mathrm{~s}$ on the surface of MWNT after ozone treatment with the inset of $\mathrm{C} 1 \mathrm{~s}$ high resolution spectra after 12 hour ozone treatment.

Table 1. Change of surface atomic percent of $\mathrm{C}$ and $\mathrm{O}$ elements for MWNT after ozone treatment

\begin{tabular}{ccc}
\hline \multirow{2}{*}{ Peak } & \multicolumn{2}{c}{ Relative Peak Intensity } \\
\cline { 2 - 3 } & Raw CNT & O3-treated CNT (12 hr) \\
\hline C1s & $97.5 \%$ & $90.0 \%$ \\
\hline O1s & $2.5 \%$ & $10.0 \%$ \\
\hline
\end{tabular}

the raw MWNT due to ozone oxidation. The inset of Fig. 2 shows the deconvoluted components of $\mathrm{C} 1 \mathrm{~s}$ peak of ozonetreated MWNT to distinguish the detailed oxidation states of carbons. Aside from the $\mathrm{C}-\mathrm{C}$ peak at $284.6 \mathrm{eV}$, the higher additional binding energies at $286.1 \mathrm{eV}$ and $289.3 \mathrm{eV}$ represent $-\mathrm{C}-\mathrm{O}$ and $-\mathrm{O}-\mathrm{C}=\mathrm{O}$ of carboxylic acid group, respectively. The oxygen values of carboxylated MWNTs calculated from XPS measurement were summarized in Table 1, which indicated that the degree of carboxylic acid modification was higher than $7 \%$.

Fig. 3 shows the solubility of raw and ozone-treated MWNT in water and benzene. The results clearly revealed that the solubility of the raw MWNT was improved when they were dispersed water, a typical polar medium. However, when they were dispersed in non-polar solvents, benzene, the amount of material solubilized was negligible by precipitating to the bottom of the solution after several minutes. This can be attributed to the presence of oxidized groups that disrupt the charge symmetry, creating dipoles, although the momentary interactions were not sufficiently strong to overcome the large van der Waals forces between the CNTs [11]. Moreover, it is notable that dispersive stability of MWNT in water can be attained by ozone treatment in a dry state, which is important for the bio-application of MWNT.

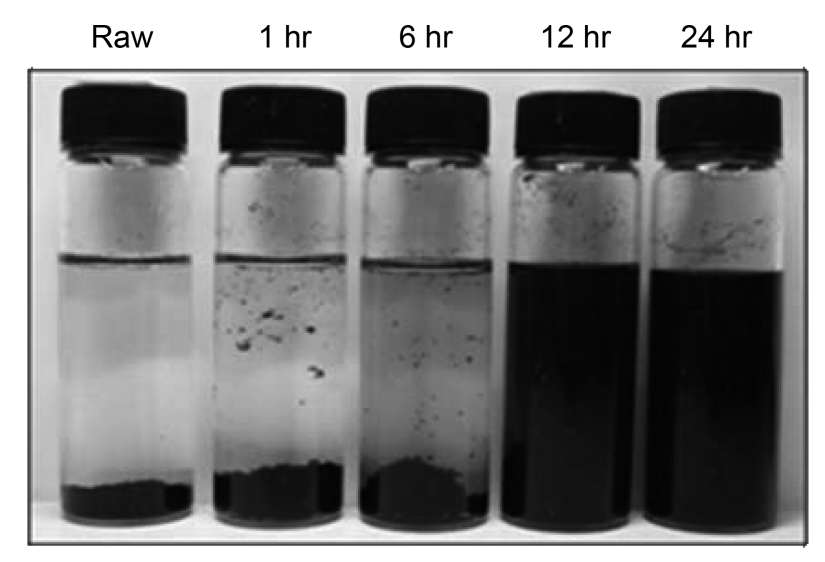

(a) In water

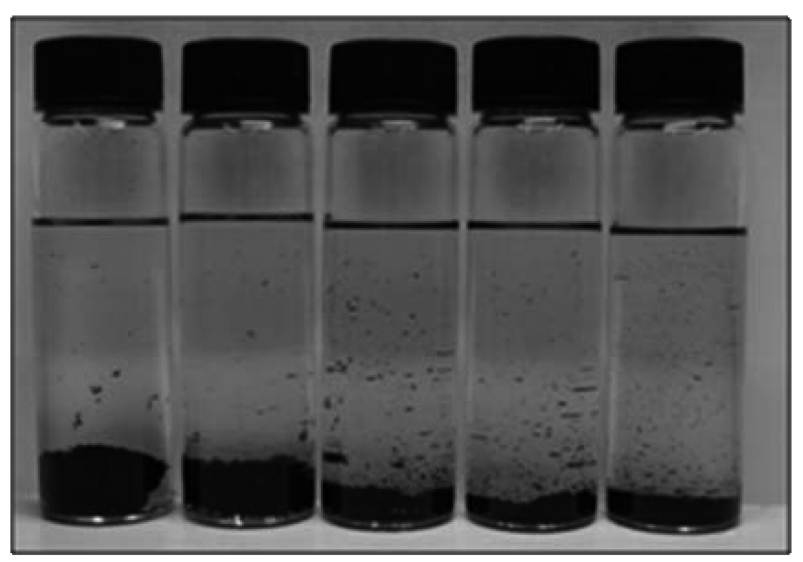

(b) In benzene

Fig. 3. Effect of ozone treatment on the dispersive stability of MWNT in water (a) and benzene (b) after 7 days, as a function of ozone exposure time.

Combined to the FTIR, XPS, and solubility in liquids, it could be concluded that the oxygen containing functional groups produced during the dry ozone gas exposure of MWNT, and the treated MWNT should have similar chemical nature to those from the acid treatment.

\subsection{Effect of ozone treatment on the morphology and thermal stability of $M W N T$}

Fig. 4 gives the change of the MWNT morphology before and after ozone-treatment characterized by scanning electron microscopy. As shown in the figure, up to $24 \mathrm{hrs}$ ozone treatment, the shape and the aspect ratio of MWNT almost kept the same as that of raw MWNT, while the MWNT morphology after $30 \mathrm{~h}$ treatment are greatly altered by significant damage. Thus, amorphous-like carbon particulates are mostly formed. These damaging effects result in severe degradation in mechanical properties of MWNT as well as disruption of p-electron system in CNT. 


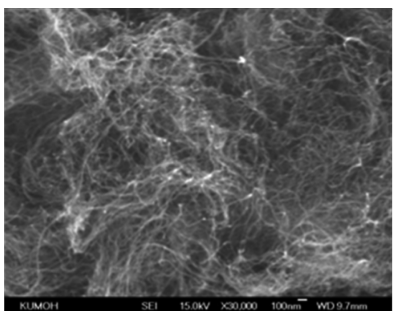

Raw

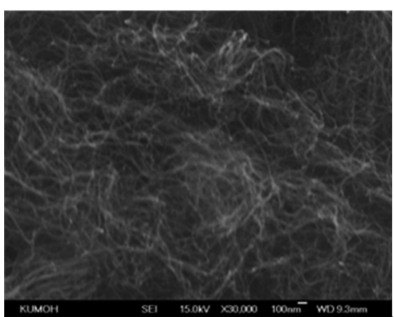

$24 \mathrm{hr}$

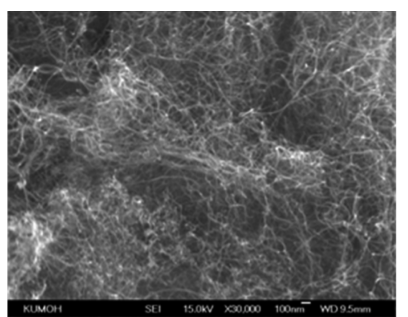

$12 \mathrm{hr}$

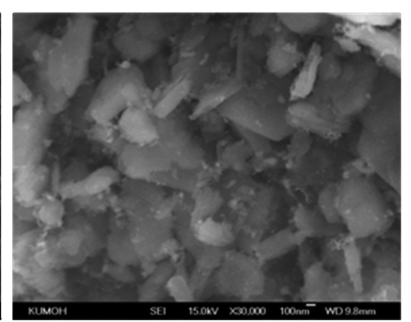

$30 \mathrm{hr}$
Fig. 4. Change of MWNT morphology according to the treating time under ozone flow.

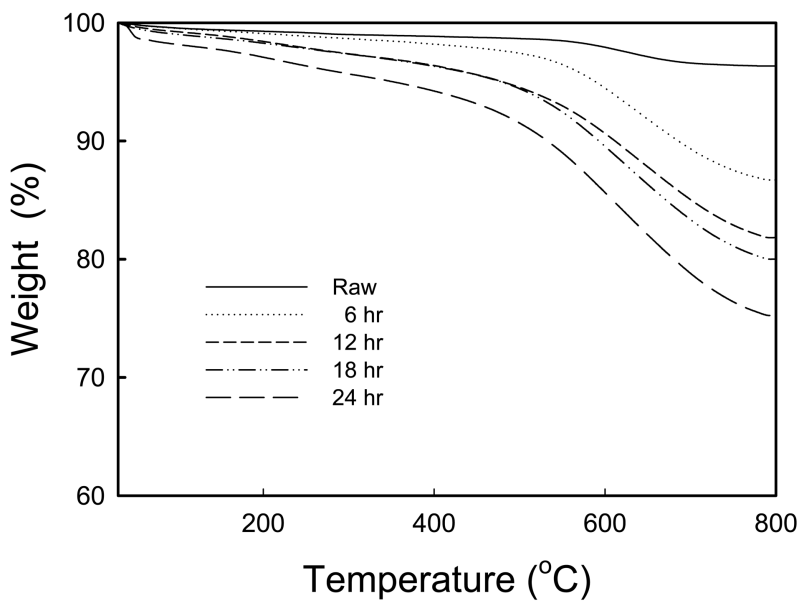

Fig. 5. TGA thermograms showing effect of ozone treatment time on the thermal stability of MWNT.

In order to investigate the effect of ozone treatment on the thermal stability of MWNT, TGA measurements were carried out. Fig. 5 shows the mass of MWNT samples as a function of ozone exposure time and temperature. As shown in the figure, MWNT having more physical defect sites by introduction of functional groups on the surface as well as end-cap would be expected to show a decrease in weight at a lower temperature. It is clear from the figure that raw MWNT was quite stable at temperatures up to $600^{\circ} \mathrm{C}$ in an air atmosphere, while the degradation of ozone treated MWNT was initiated at low temperatures indicating the severe damage produced during the ozone treatment. Such loss in the mass is known due to the escape of $\mathrm{CO}_{2}$ gas produced during oxidation of nanotubes [15].

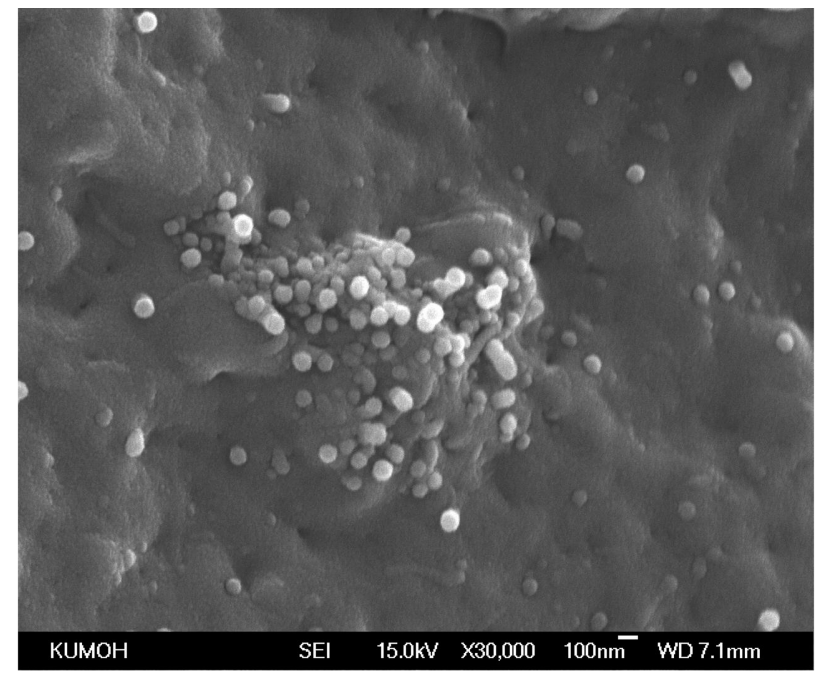

(a)

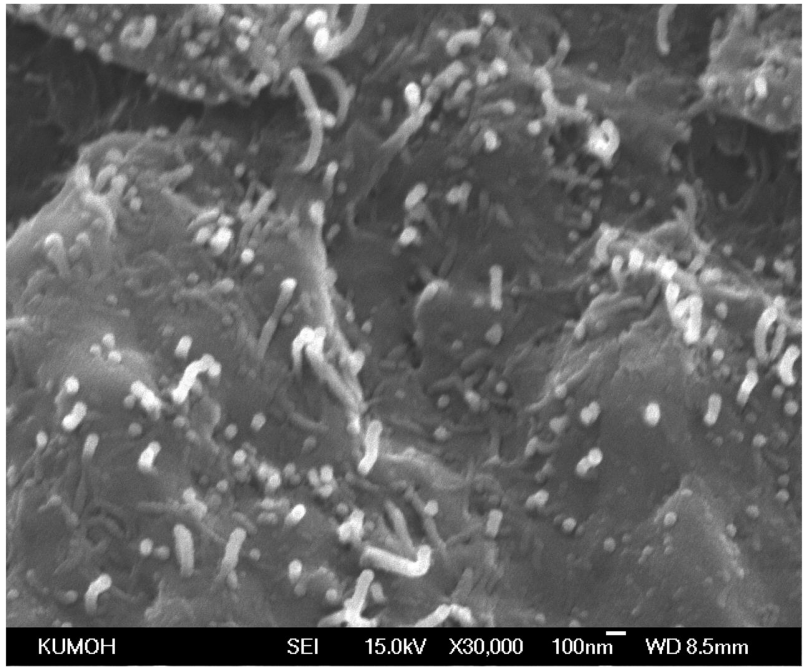

(b)

Fig. 6. A typical dispersive morphology of PA6/MWNT nanocomposites prepared with $5 \mathrm{wt} \%$ MWNT before (a) and after (b) ozone treatment for $12 \mathrm{hrs}$.

\subsection{Effect of ozone treatment of MWNT on the morphology and mechanical properties of PA6/MWNT nanocomposites}

The effect of ozone treatment of MWNT on the morphology and mechanical properties of the reinforced nanocomposite of PA6 and MWNT was evaluated by observing the fractured cross-section and measuring the tensile and impact properties of the composites. The representative FE-SEM photographs of the cross-sectional fracture of the composites with raw and modified MWNT are shown in Fig. 6. The dispersion of raw MWNT was found to be poor in the PA6 matrix, as shown in Fig. 6(a) at $5 \mathrm{wt} \%$ of MWNT. Furthermore, the agglomerates of MWNT 


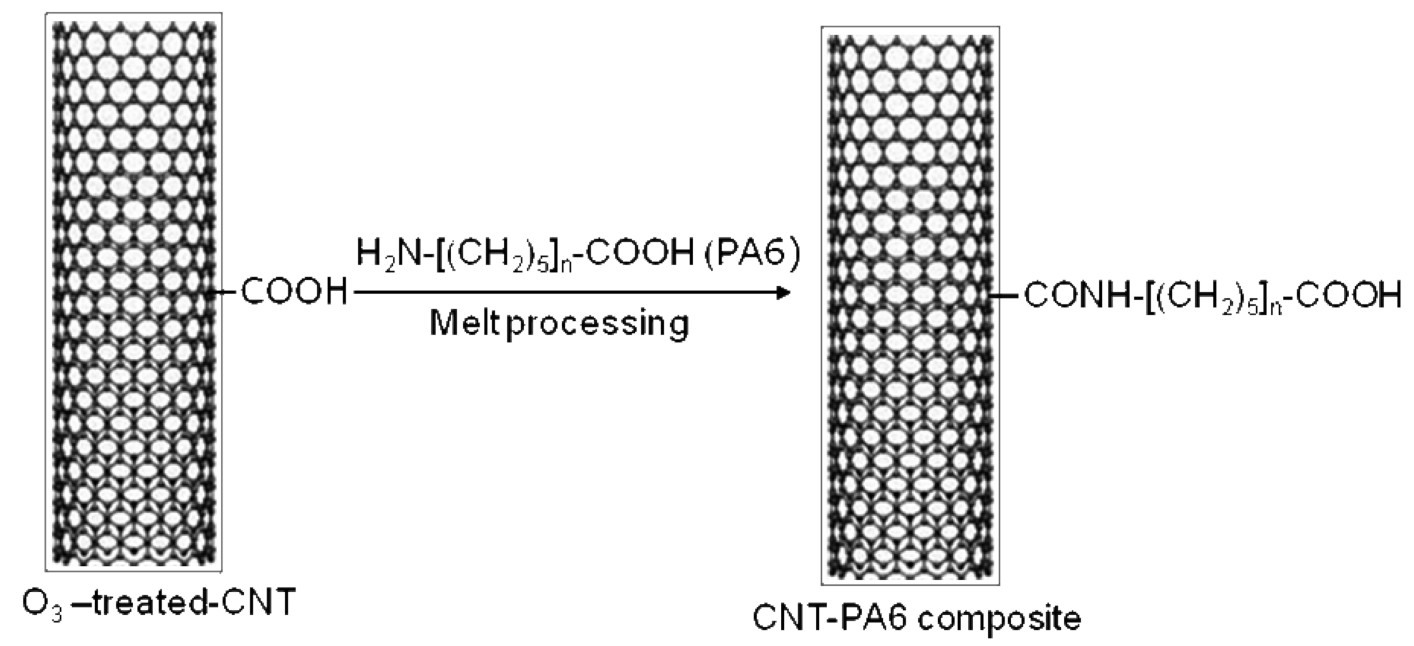

Fig. 7. Expected covalent bonding by melt compounding of ozone treated MWNT and PA6.

were observed in the PA6 matrix, reducing the reinforcing effects of the MWNT. The dispersion of MWNT, however, was notably improved for the composite prepared with ozone treated MWNT.

As found in the spectroscopic analyses, the functionalized MWNT by ozone treatment contained many acid groups. The incorporation of the functionalized MWNT into PA6 matrix creates some interaction between MWNT and PA6 chains, thus being favorable to both dispersion and stress transfer. Fig. 7 represents the presumable chemical interaction between the basic end groups of PA6 and acidic functional groups on MWNT, which was formed during melt compounding. These interactions would be the main reason for the improvement in dispersion of MWNT in PA6 matrix.

Furthermore, the chemically functionalized MWNT can produce strong interfacial bonds with some polymers allowing MWNT-based nanocomposites to possess high mechanical properties. The tensile strength and initial modulus PA6/MWNT composites are illustrated in Fig. 8. Tensile strength of the composites showed a decreasing tendency when the raw MWNT was incorporated up to $1.5 \mathrm{wt} \%$ mainly due to poor dispersion of MWNT in the PA6 matrix and poor adhesion between MWNT and PA6. Thus, it is considered that the agglomerates of raw MWNT in PA6, as seen in the FE-SEM image, act not as reinforcing agent but as defects. The composite with ozone treated MWNT, however, slightly increased with increasing of MWNT content presumably due to the improvement in dispersion of MWNT as well as adhesion between the reinforcement and the matrix, as represented schematically in Fig. 7.

On the other hand, the initials modulus of the composites reveals a similar increasing trend regardless of modification of MWNT, even though the composite with modified one shows a slightly higher value compared to that with raw MWNT.

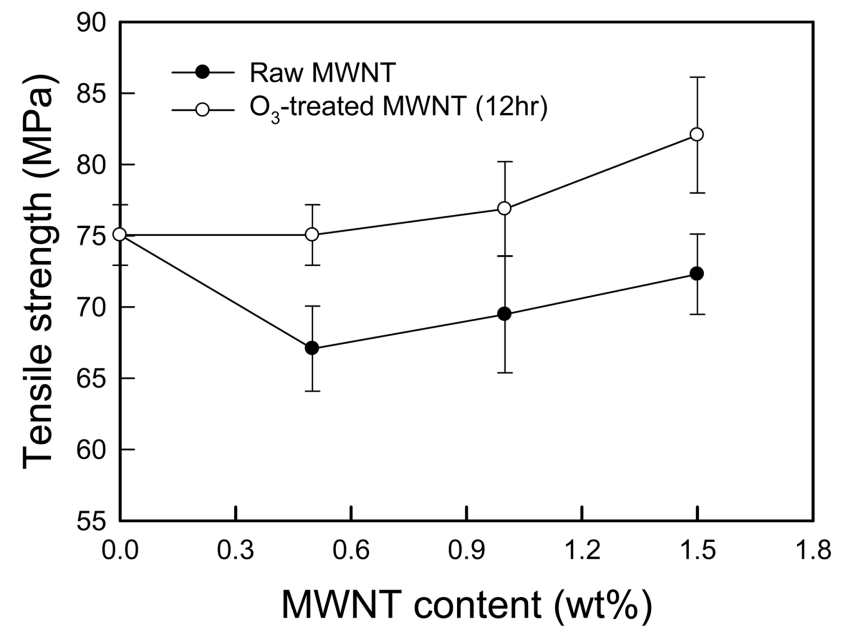

(a)

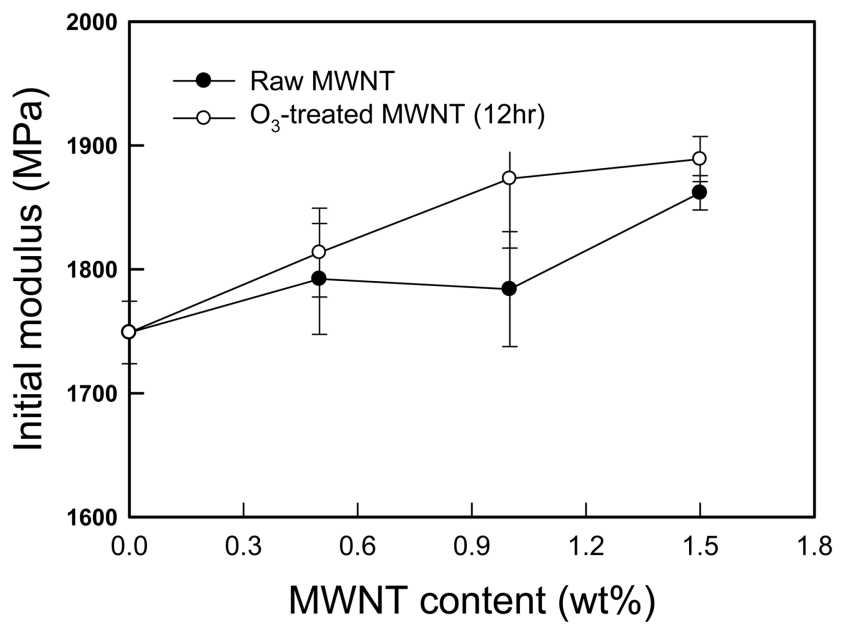

(b)

Fig. 8. Effect of ozone treatment of MWNT on the tensile strength (a) and modulus (b) of PA6/MWNT nanocomposites. 


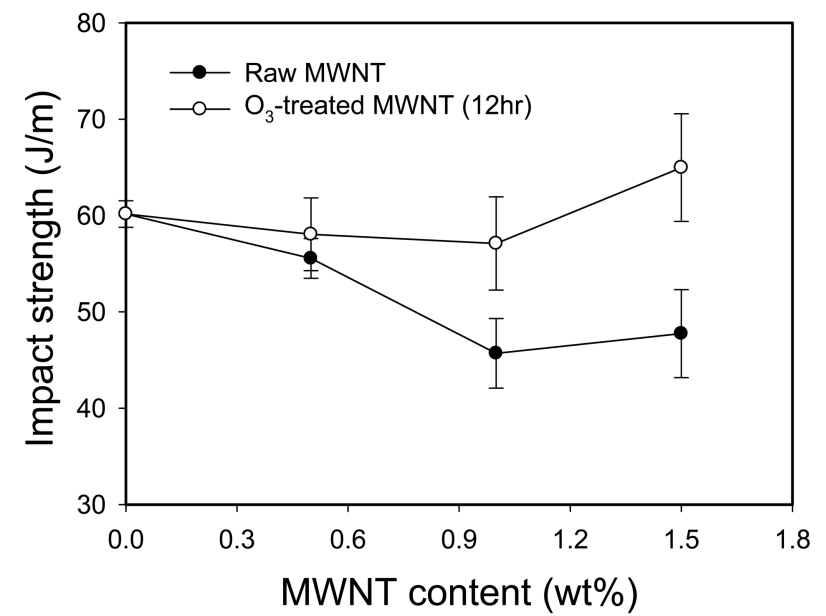

Fig. 9. Effect of ozone treatment of MWNT on Izod impact strength of PA6/MWNT nanocomposites.

Fig. 9 gives the impact strength of PA6/MWNT composites as a function of MWNT content. MWNT dispersion and adhesion to the matrix is much more critical for the improvement of impact strength of the composites than for that of tensile properties, particularly in the case of polymeric matrix with relatively high impact strength such as PA6. As can be seen in Fig. 9, the raw MWNT didn't provide some additional toughening effects to PA6 matrix. On the contrary, the raw MWNT resulted in significant reduction in impact strength of PA6. This reduction, however, was retarded when ozone-modified MWNT was incorporated to PA6 by keeping the value of neat PA6.

Thus, the ozone treated MWNT showed significantly improved mechanical properties of the composites, compared to the raw MWNT.

\section{Conclusions}

Useful functional groups onto the MWNT surface could be introduced by a dry oxidizing process using ozone gas flow. Combined to the FTIR, XPS, and solubility in liquids, it could be concluded that the dry ozone gas exposure introduces polar functional groups such as carboxylic groups to MWNT similar to acidic modification of MWNT. Consequently, the hydrophilic functional groups on the MWNT introduced by ozone oxidation were helpful in improving the interaction with functional groups in PA6 such as $-\mathrm{NH}_{2}$ and $-\mathrm{CONH}-$. Therefore, the strong interaction between the functionalized MWNT and PA6 matrix greatly enhanced the dispersion as well as the interfacial adhesion. As a result, the overall mechanical performance of the composites could be improved. Particularly, the stable dispersion of MWNT in water after ozone treatment above a critical level is expected to show potential bio-application.

\section{Acknowledgements}

This research was financially supported by the Ministry of Knowledge Economy (MKE) through the Project of Industrial Source Technology.

\section{References}

[1] Wong, E. W.; Sheehan, P. E.; Lieber, C. M. Science 1997, 277, 1971.

[2] Tans, S. J.; Verschueren, A. R. M.; Dekker, C. Nature 1998, 393, 49.

[3] Berber, S.; Kwon, Y. K.; Tománek, D. Phys. Rev. Lett. 2000, 84, 4613.

[4] Sahoo, N. G.; Rana, S.; Cho, J. W.; Li, L.; Chan, S. H. Prog. Polym. Sci. 2010, 35, 837.

[5] Peng, K.; Liu, L-Q.; Li, H.; Meyer, H.; Zhang, Z.; Carbon, in press.

[6] Kim, J. Y.; Han, S.; Hong, S. Polymer 2008, 49, 3335.

[7] Eitan, A.; Jiang, K. Y.; Dukes, D.; Andrews, R.; Schadler, L. S. Chem. Mater. 2003, 15, 3198.

[8] Eitan, A.; Jiang, K. Y.; Dukes, D.; Andrews, R.; Schadler, L. S. Comp. Sci. Tech. 2006, 66, 1162.

[9] Mawhinney, D. B.; Naumenko, V.; Kuznetsova, A.; Yates, J. T.; Liu, J.; Smalley, R. E. J. Am. Chem. Soc. 2000, 122, 2383.

[10] Maa, P.-C.; Siddiquia, N.; Marom, G.; Kim, J.-K. Composites: Part A 2010, 41, 1345.

[11] Najafi, E.; Kim, J. Y.; Han, S. H.; Shin, K. W. Coll. Surf. A: Physicochem. Eng. Aspects 2006, 284, 373.

[12] Lu, C.; Su, F.; Hu, S. Appl. Surf. Sci. 2008, 254, 7035.

[13] Zeng, L.; Wang, W.; Liang, J.; Wang, Z.; Xia, Y.; Lei, D.; Ren, X.; Yao, N.; Zhang, B. Mat. Chem. Phys. 2008, 108, 82.

[14] Mawhinney, D. V.; Naumenko, V.; Kuznetsova, A.; Yates, J. T. J. Am. Chem. Soc. 2000, 122, 2283.

[15] Adhikari, A. R.; Huang, M. B.; Bakhru, H.; Talapatra, S.; Ajayan, P. M.; Ryu, C. Y. Nucl. Inst. Meth. Phys. Res. B 2006, 245, 431. 